This item was submitted to Loughborough's Research Repository by the author.

Items in Figshare are protected by copyright, with all rights reserved, unless otherwise indicated.

\title{
Emergency Department response to Chemical, Biological, Radiological, Nuclear, and explosive events: a systematic review
}

PLEASE CITE THE PUBLISHED VERSION

https://doi.org/10.1017/S1049023X18000900

\section{PUBLISHER}

(c) World Association for Disaster and Emergency Medicine. Published by Cambridge University Press

\section{VERSION}

AM (Accepted Manuscript)

\section{LICENCE}

CC BY-NC-ND 4.0

\section{REPOSITORY RECORD}

Hignett, Sue, Saydia Razak, and Jo Barnes. 2019. "Emergency Department Response to Chemical, Biological, Radiological, Nuclear, and Explosive Events: A Systematic Review". figshare.

https://hdl.handle.net/2134/34646. 


\section{Prehospital and Disaster Medicine}

国国国 CAMBRIDGE

\section{Emergency Department response to Chemical, Biological, Radiological, Nuclear, and explosive events: A Systematic Review}

\begin{tabular}{|r|l|}
\hline Journal: & Prehospital and Disaster Medicine \\
\hline Manuscript ID & PDM-18-0092.R1 \\
\hline Manuscript Type: & Comprehensive Review \\
\hline Keywords: & CBRNe, Detection, Decontamination, Diagnosis, Emergency Department \\
\hline \multicolumn{2}{|l}{} \\
\hline
\end{tabular}

SCHOLARONE $^{\mathrm{m}}$

Manuscripts 


\section{Keywords}

CBRNe, Detection, Decontamination, Diagnosis, Emergency Department

\section{Abbreviations}

ED: Emergency Department

ET tube: Endotracheal Tube

CBRNe: Chemical, Biological, Radiological, Nuclear, and explosive

CBR: Chemical, Biological, and Radiological

IOR: Initial Operational Response

PRISMA: Preferred Reporting Items for Systems for Systematic Reviews and Meta-Analyses

LMA: Laryngeal Mask Airway

MMAT: Mixed Method Appraisal Tool

ORCHIDS: Optimisation through Research of CHemical Incident Decontamination Systems

PPE: Personal protective Equipment 


\begin{abstract}
Introduction

A Chemical, Biological, Radiological, Nuclear, and explosive (CBRNe) event is an emergency which can result in injury, illness, or loss of life. The Emergency Department (ED) as a health system is at the forefront of the CBRNe response with staff acting as first receivers. EDs are underprepared to respond to CBRNe events - recognising key factors which underlie the ED CBRNe response is crucial to provide evidence-based knowledge to inform policies and most importantly clinical practice.
\end{abstract}

\title{
Problem
}

Challenges in detection, decontamination and diagnosis are associated with the ED CBRNe response when faced with self-presenting patients.

\section{Methods}

A systematic review was carried out in accordance with Preferred Reporting Items for Systematic Reviews and Meta-Analyses (PRISMA). An in-depth search strategy was devised to identify studies which focused on the ED and CBRNe events. The inclusion criteria was stringent in terms of the environment (ED), participants (first receivers), situation (CBRNe response), and actions (detection, decontamination and diagnosis). Fifteen databases and topic-specific journals were searched. Studies were critically appraised using the Mixed Methods Appraisal Tool (MMAT). Papers were thematically coded and synthesised using NVivo 10. 


\section{Results}

Sixty-seven full-text papers were critically appraised using the MMAT; 70\% were included $(n=60)$ as medium or high quality studies. Data were grouped into 4 themes: preparedness, response, decontamination, and Personal Protective Equipment (PPE) problems.

\section{Discussion}

This study has recognised the ED as a system which depends on four key factors preparedness, response, decontamination, and PPE problems which highlight challenges, uncertainties, inconsistencies, and obstacles associated with the ED CBRNe response. This review suggests that response planning and preparation should be considered at three levels: organisational (policies and procedures); technological (decontamination, communication, security, clinical care, and treatment); and individual (willingness to respond, PPE, knowledge, and competence). Finally, this study highlighted that there was a void specific to detection and diagnosis of CBRNe exposure on self-presenting patients in the ED.

\section{Conclusion}

The review identified concerns for both knowledge and behaviours which suggests that a systems approach would help understand the ED response to CBRNe events more effectively. The four themes provide an evidence-based summary for the state of science in ED CBRNe response which can be used to inform future policies and clinical procedures. 


\section{Introduction}

Chemical, Biological, Radiological, Nuclear, and explosive (CBRNe) events occur through natural, accidental, and deliberate means ${ }^{1}$. CBRNe events present a threat to human welfare by causing, or having potential to cause, injury, illness, or loss of life and can result in a large number of casualties.

Emergency Departments (EDs) have statutory duties and responsibilities to prepare, plan, and respond to $\mathrm{CBRNe}$ events adequately ${ }^{2}$. EDs are at the forefront of the CBRNe response and serve as the gateway to the most appropriate care of patients ${ }^{3}$. In particular employees within the ED are often considered a subset of first responders in such incidents ${ }^{4,5}$. ED staff are termed 'first receivers ${ }^{6}$ and include doctors, nurses, allied healthcare professionals, and non-clinical staff for initial recognition (receptionists); cordon control (security); and general support (estates/porters) during the CBRNe response ${ }^{7}$.

\section{The problem}

Patients arrive at the ED by ambulance or self-presentation. If they have been brought in by an ambulance they receive a medical assessment and care by paramedics whilst waiting to be allocated an ED cubicle. Patients who self-present are not provided with this assessment or care $^{8}$. This introduces challenges in the ED CBRNe response, particularly in terms of detection of a contaminant on a self-presenting patient at the ED triage or waiting area ${ }^{6}$. Another associated challenge related to self-presenters and the ED response is decontamination, defined as "the reduction or removal of harmful substances from the body"

${ }^{9}$; this is an area of ambiguity and is negatively associated with the donning of PPE. Finally, the diagnosis of CBRNe related symptoms is difficult due to the rarity of these events and similarity with other diseases making exposure difficult to diagnose ${ }^{10}$. 
EDs are underprepared to efficiently respond to CBRNe events ${ }^{11-15}$. Previous research has focused on training, namely doctors and nurses ${ }^{5,16}$ to overcome unpreparedness. Training as the sole means of enhancing the ED CBRNe response is questionable because obstacles such as short staffing and constant staff turnover arise ${ }^{6}$. The purpose of this review was to scope the ED CBRNe response with respect to detection, decontamination, and diagnosis of selfpresenting patients to identify key factors which can inform future policies and clinical procedures.

\section{Report}

\section{Method}

The seven-stage framework was used in line with the PRISMA statement (www.prismastatement.org). This provides structured guidance on the development of appropriate research questions, as well as on the eligibility of search criteria, and the identification, selection, retrieval, appraisal, and synthesis of relevant papers according to title and abstract.

Research question: What is known about the ED CBRNe response with respect to detection, decontamination, and diagnosis of self-presenting patients?

Eligibility: References were screened at the first stage by setting the database parameters to all languages (English abstract), post 2001, worldwide, and any study type.

Search: The search started by scoping and exploring concepts related to the research question. An initial set of keywords was tested in BNI (NHS evidence) and Google Scholar using the string searches in Figure 1. The results were reviewed for relevance, and additional keywords were added from retrieved references. The search was divided into four areas to combine concepts of environment $(A)$, areas of exploration $(A+B)$, context $(A+B+C)$ and types of patients $(\mathrm{A}+\mathrm{B}+\mathrm{C}+\mathrm{D})$. 
A. Emergency Department, Accident and Emergency and Emergency Room.

B. Detection, decontamination, and diagnosis.

C. CBRNe, CBRN, Mass-casualty Incidents, and MCI.

D. Walking wounded, priority 3 (P3; mobile with minor injuries), and self-presenters.

Figure 1

The search was run on 15 databases: ProQuest, ASSIA, BNI (NHS Evidence), Chemical Database service, Ergonomics Abstracts, Google Scholar, Health Management Technology (EBSCO), Medline (Ovid SP), PsychInfo (EBSCO), Referex (Materials and Mechanical Engineering), SAE digital library, Scopus (Elsevier), Science Direct, Toxline and Web of Science. Additional searches were run in topic-specific journals e.g. Journal of Breath Research and Trends in Analytical Chemistry as shown in Table 1.

Identification of relevant papers (inclusion/exclusion): Papers were included where they reported research in ED (only); ED staff (including surgeons, anaesthetists, operational managers, and ED Chiefs); mass-casualty incident by the intentional release of CBRNe materials, ED triaging; and detection, decontamination, and diagnosis in ED including donning PPE. Papers were excluded from guidelines, textbooks and grey literature. Scientific studies of the effects of CBRNe materials, i.e. physiological and chemical pathways, were excluded. Psychological or psychosocial effects of CBRNe incidents were excluded. Finally, research reporting on activity in hot zones was excluded.

Selection and retrieval: The search identified 1,874 papers which were screened by title and abstract, and checked for duplication, resulting in 366 papers. Articles that did not adhere to the inclusion criteria were disregarded whilst simultaneously adding (23) relevant studies 
through manual citation searches. This resulted in the quality of 67 articles being assessed with the Mixed Methods Appraisal Tool (MMAT).

Appraisal: The included papers $(\mathrm{n}=67)$ were appraised using the $\mathrm{MMAT}^{17}$ to assign a quality score on a 5 point scale from 0 to $4(100 \%$ of criteria met). Seven papers scoring 0 or 1 $(<25 \%)$ were discarded, as the quality was too poor for inclusion. This resulted in a final number of sixty studies (Figure 2).

Synthesis: The residual studies $(n=60)$ were retained for qualitative synthesis. There were 4 emerging themes of CBRNe preparedness $(n=38)$, response $(n=29)$, decontamination $(n=9)$, and PPE problems $(n=9)$. Some papers provided information for more than one theme.

\section{Results}

Papers were included from 12 countries: USA, UK, Israel, Canada, Australia, Pakistan, Singapore, Turkey, Ireland, Italy, Norway, and Spain. The methodological quality of the included papers were mostly medium and strong (Table 2, supplementary online material). A quantitative synthesis was not carried out based on the variation in study types, sample populations, study aims, and multi-faceted nature of CBRNe events.

Figure 2

Included papers were coded in Nvivo 10 (QSR International Ltd, Melbourne, Australia), for thematic analysis. Overlapping themes between studies were coded and then grouped into main themes, which highlighted key factors relevant to the research question, as outlined below. 


\section{Preparedness}

Preparedness was associated with a post-9-11 shift in thinking ${ }^{18,19}$ which forced EDs to examine and update their emergency disaster preparedness plans ${ }^{20}$. Such as dividing ED CBRNe preparedness into two domains- departmental and individual ${ }^{5}$.

This systematic review identified the ED as a system and preparedness consisting of three inter-twining levels: organisation, technology, and individual (see Table 3). With studies reporting research on organisational preparedness to provide timely and high standard care to patients ${ }^{5,13,21,22}$ particularly emphasising standardised measures ${ }^{16,23}$ competencies ${ }^{24,25}$ and standards ${ }^{13}$ for ED CBRNe preparedness.

Technology-related preparedness both includes and highlights limitations in communication systems to co-ordinate the CBRNe response ${ }^{26}$; mainly the unreliability of mobile phones and walkie-talkies, due to reception difficulties particularly when surrounded by certain materials. Additionally, computer-based decision-support systems were anticipated to be overwhelmed due to the surge in patients, resulting in a preference for manual pen-paper methods ${ }^{27,28}$. Individual preparedness was associated with the perceptions, perspectives, views, and information needs of first receivers which affected their capacity to respond to CBRNe events $29,30$.

In addition to communication issues, there was also evidence that EDs lack preparedness (including capacity) for decontamination, security, appropriate equipment, antidotes, and treatment equipment incapacities ${ }^{12,22,31,32}$. Furthermore one study suggested that the limitations in the ED CBRNe response was a reflection of overall hospital preparedness ${ }^{33}$. 


\section{Response}

Numerous studies reported on individual staff skills or preferences in responding to a CBRNe event. By which the response was determined by the individual first receivers' willingness to respond to a CBRNe event. Individual willingness to respond varied based on the type of event with the majority of first receivers more willing to respond to disasters such as an aeroplane crash, in comparison to radioactive or biological exposure ${ }^{34}, 35$. Nonetheless, willingness to respond was found to be high for Chemical, Biological, and Radiological events amongst ED nurses with postgraduate qualifications however this willingness to respond to CBR exposure decreased significantly if the substances were unknown ${ }^{30}$. Studies reported a number of solutions to enhance the ED CBRNe response, including creating surge capacity ${ }^{21,36}$ - which is the hospitals ability to accommodate a transient sudden rise in demand for healthcare following an event ${ }^{21,36}$. Implementing specific triage routes (time and sequence for patient management) have been proposed to create surge capacity ${ }^{37,38}$ as well as applying actions such as a decrease in new admissions, discharge of patients earlier, cancelling elective surgeries, organising day care for children of staff, and designating victim flow areas ${ }^{11,39,40}$. Surge capacity was however, suggested to be restricted by the failure to fully integrate interagency training, planning, and co-ordination ${ }^{11,21,36}$.

\section{Decontamination}

The importance of effective decontamination within the ED was emphasised by a number of studies ${ }^{13,41,42}$. They suggested it was imperative for EDs to have the appropriate facilities, equipment, and capability to respond to CBRNe exposure.

Decontamination challenges related to knowledge and facilities were reported for PPE, clinical waste management, and decontamination timescales ${ }^{5,43,44}$. Variation existed between studies in terms of having the facilities to physically decontaminate patients. For example, 
some EDs had designated areas for decontamination ${ }^{13,45}$ but could not manage a serious chemical incident as a result of lack of equipment. Other studies highlighted a lack of decontamination facilities overall ${ }^{23,46}$ and some identified factors which restricted capability to decontaminate effectively. These factors included equipment ${ }^{13,16,45}$ and knowledge relating to decontamination procedures. It was reported that decontamination knowledge was flawed in terms of how to carry out decontamination and the associated time scales ${ }^{13}$. There was also a lack of knowledge in water flow procedures to prevent cross-contamination, clinical waste management, and the potential of cross-contamination in general ${ }^{5,45}$.

\section{Personal Protective Equipment problems}

First receivers were found to hold negative perceptions of PPE finding it cumbersome - in particular ED nurses found difficulties in donning PPE with specific limitations including poor suit fit, poor mask fit, claustrophobia, pregnancy, glasses or beard that prevents adequate mask seal, as well as respiratory or cardiovascular illness ${ }^{13,30,47}$.

Several papers identified PPE challenges for routine and lifesaving tasks including inadequate provision ${ }^{45}$, poor fit, and dexterity issues ${ }^{13,30,47}$. Coping strategies were reported to include substitute equipment whilst wearing PPE for example prefilled (Aurum) syringes to administer intravenous drugs, instead of the traditional glass ampules and syringe method ${ }^{47}$. Another substitution was using a Laryngeal Mask Airway (LMA) rather than and Endotracheal (ET) tube to secure the patients airway if required ${ }^{41,48,49}$. 


\section{Discussion}

This state of science review has systematically searched for, and reviewed research on the ED response to a CBRNe event. It has recognised the ED as a system which depends on key factors when responding to such an event. The themes - preparedness, response, decontamination, and PPE problems were identified as key factors based on research highlighting challenges, uncertainties, inconsistencies, and obstacles associated with the ED CBRNe response.

In line with existing literature, this review highlights that first receivers are underprepared to respond to a CBRNe event as they would natural disasters ${ }^{20,23,30,35,50}$, resulting in the ED being underprepared effectively respond overall. An explanation is that the ED is a complex system consisting of organisational, technological, and individual factors, which is further complicated by multifaceted CBRN events. Although it is suggested that hospitals should implement policies to address the lack of preparedness ${ }^{51}$; a means of better understanding the ED as a system is by adopting a systems approach, which accounts for, and improves the design of a system and peoples interaction with it, rather than concentrating on an individual part of it ${ }^{52}$.

Further, first receivers display an unwillingness to respond to CBRNe events due to perceived risk, which has previously been associated with invisible hazards ${ }^{53}$ associated with CBRNe events, and an unwillingness of staff to respond ${ }^{54}$, resulting in staff shortages ${ }^{55}$ compromising an effective response.

Additionally, literature based on response suggested that aspects such as surge capacity would be compromised as a result of limited interagency co-ordination ${ }^{21,36}$. A suggested means of creating surge capacity is that of triaging patients efficiently. Effective triage was demonstrated through retrospective studies of explosive events ${ }^{39,56,57}$. These studies 
highlighted varying techniques of triage and how they impacted surge capacity and the care offered to patients. They also demonstrated that experience and expertise were often overcome by the overwhelming surge of patients.

Studies based on decontamination, emphasised that it remained an area of ambiguity in the ED CBRNe response ${ }^{16}$, particularly in terms of providing adequate facilities and equipment to perform decontamination ${ }^{13,45}$. This disconnect is amplified by the incapability of first receivers to carry out decontamination, resulting from their lack of knowledge on how to carry out decontamination procedures ${ }^{5,13}$.

Studies identifying PPE problems highlighted the inadequate provision of PPE ${ }^{29,45}$. This is further complicated by first receivers having limited knowledge about the application of PPE, finding it cumbersome, and having limited dexterity when conducting both routine and lifesaving procedures ${ }^{13,30,47}$. Compensatory type studies focusing on overcoming PPE problems were prevalent. For example, a recent study which proposed the use of a lighter, size-specific PPE suit ${ }^{58}$ which overcomes the physical constraints of PPE. The suggestion is that trial and error will continue until both routine and lifesaving tasks can be carried out in PPE competently and comfortably.

On a local level, the findings from this review can be used to formulate a check sheet for ED disaster planners in order to enhance planning, preparedness, and response to CBRNe events, as shown in Figure $3^{+}$.

Figure 3 
${ }^{+}$This checklist is entirely based on the literature included in this review. It is likely to have omissions, and should only be used in context of the presenting CBRNe situation combined with up-to-date governmental guidance.

The findings from this systematic review can further be used to inform CBRNe guidance. For example, in the UK, The Health Protection Agency (HPA) ${ }^{59}$ has published clinical guidelines on how to respond to CBRNe events in the ED. The HPA guidance explains how to safely clinically recognise, respond, and treat exposure which is dependent on presenting symptomologies. Mnemonics for rapidly assessing casualties, triaging sieves, guidance on the type of PPE required as well as useful contacts are provided in this guidance ${ }^{59}$. The link between effective triage and surge capacity highlighted through this review can contribute to revisions of future HPA guidance.

Emergency Preparedness Resilience and Response (EPRR) ${ }^{60,61}$ is another initiative in the UK, providing guidance in CBRNe response. The guidance for self-presenters focuses on chemical exposure ${ }^{60}$ and is based on findings from the "Optimisation through Research of CHemical Incident Decontamination Systems" (ORCHIDS) ${ }^{62}$ project as its empirical framework to better respond to incidents involving hazardous materials. The guidance suggests rapid actions to save lives, known as the Initial Operational Response (IOR) to improve patient outcomes following CBRN exposure ${ }^{63}$. Findings from this systematic review can inform EPRR guidance to recognise first receivers decreased willingness to respond to unknown chemical exposure in comparison to known chemical hazards ${ }^{30}$. Furthermore in order to implement the IOR, this review emphasises the need for appropriate facilities, equipment, and capability to carry out decontamination to be ready and available.

With reference to the research question and the challenges of detection, decontamination, and diagnosis, this review found that research investment was being made in decontamination, 
and the ORCHIDS project adds to this. However, there were no specific studies on the detection or diagnosis of exposure. In terms of the ED responding to self-presenters, this review found that the willingness to respond to CBRNe contaminated casualties' decreases when the substance is unknown.

\section{Limitations}

The majority of the data used in this study was retrospective event based data which can be considered to jeopardise the scientific quality and validity of findings ${ }^{64}$. However, retrospective event data particularly in disaster medicine is the norm. It is suggested that every systematic review faces challenges in terms of the quality of data collected ${ }^{64}$.

There was also a geographical and publication bias with 20 of the 60 studies conducted in the US. This contributes to an acknowledged bias towards US literature as a point of reference in UK Health emergency planning and preparedness evidence ${ }^{65,66}$.

\section{Conclusion}

Understanding the key factors underpinning the dynamic ED system to plan, prepare, and respond to emergencies effectively has major legal, clinical, and moral implications. ED preparedness and response has obstacles, uncertainties and inconsistencies in addition to the known challenges. The four themes provide an evidence-based summary to inform future CBRNe guidance, policies, and clinical procedures. The themes particularly identify that the ED CBRNe response is limited unless response planning and preparation is considered at three levels: organisational (policies and procedures); technological (decontamination, communication, security, clinical care and treatment); and individual (willingness to respond, PPE, knowledge and competence). Further, the complexity of the ED, the multifaceted nature of CBRNe events combined with the identified concerns from this review, in terms of both 
knowledge and behaviours suggests that a systems approach is required to understand the ED CBRNe response in the future.

\section{Figures \& Tables}

Figure 1: Example of string searches

Figure 2: PRISMA flow diagram of studies included in the systematic review

Figure 3: Check sheet for ED disaster planners 
Table 1: Search results

$\left.\begin{array}{|l|l|l|l|}\hline \text { Database } & \text { Results } & \begin{array}{l}\text { Review } \\ \text { by title }\end{array} & \begin{array}{l}\text { Review by } \\ \text { abstract }\end{array} \\ \hline \text { Abstracts in technology and engineering (ProQuest) } & 0 & 0 & 0 \\ \hline \text { ASSIA (NHS evidence) } & 1 & 1 & 0 \\ \hline \text { BNI (NHS evidence) } & 535 & 465 & 70 \\ \hline \text { Cambridge University press } & 245 & 230 & 60 \\ \hline \text { Chemical Database service } & 1 & 1 & 0 \\ \hline \text { Ergonomics Abstracts } & 0 & 0 & 0 \\ \hline \text { Google Scholar } & 331 & 305 & 66 \\ \hline \text { Health Management technology (EBSCO) } & 1 & 1 & 0 \\ \hline \text { Medline (Ovid SP) } & 217 & 204 & 53 \\ \hline \text { PsychInfo (EBSCO) } & 12 & 10 & 7 \\ \hline \text { Referex- Materials \& Mechanical Engineering } & 2 & 2 & 0 \\ \hline \text { SAE- digital library-technical papers } & 0 & 0 & 0 \\ \hline \text { Scopus (Elsevier) } & 8 & 5 & 5 \\ \hline \text { Science Direct } & 406 & 400 & 71 \\ \hline \text { Toxline } & 15 & 12 & 4 \\ \hline \text { Web of Science } & 15 & 16 & 0 \\ \hline \text { Journals : Trends in analytical chemistry; Bioanalysis- } \\ \text { future science; Journal of Breath Research -IOP science; } \\ \text { Biomolecular detection and quantification; Detection- }\end{array}\right)$


Table 3: Primary, secondary, and tertiary findings

\section{Primary Findings}

4 key factors present challenges to the ED CBRNe response:

1. Preparedness $5,12,13,16,18,19,20,21,22,24,25,26,27,28,29,30,31,32,33$

The ED is a complex system consisting of organisational, technological, and individual factors which is further complicated by the multifaceted demands of CBRNe events, resulting in under preparedness

\section{Response $\mathbf{~}^{11,21,30,34,35,26,36,37,38,39,40}$}

Response is determined by first receivers willingness to respond to unknown CBRNe exposure and the organisational management of surge capacity

\section{Decontamination $5,13,16,23,41,42,43,44,45,46$}

Decontamination remains an area of ambiguity, amplified by first receivers lack of knowledge on decontamination procedures

4. PPE problems $13,30,41,45,47,48$

Inadequate PPE provision, dexterity issues, and cumbersome fit results in PPE problems

Secondary findings

Response planning and preparation should be considered on 3 levels*:

\section{Organisational ${ }^{5}$}

- Policies and procedures

\section{Technological ${ }^{12,22,26,31,32}$}

- Decontamination ${ }^{13,41,42}$

- Communication ${ }^{27,28}$

- Security $^{12,22,31}$

- Clinical care $39,56,57$

- $\quad$ Treatment ${ }^{22,31,32}$

\section{Individual ${ }^{29,30}$}

- Willingness to respond ${ }^{34,35}$

- $\quad \mathrm{PPE}^{13,41,47,48,49}$

- Knowledge $\mathrm{K}^{30,51}$

- Competence e, $^{30}$

*Please see check sheet for ED disaster planners

Tertiary findings

1. Research on decontamination is being carried out

\section{No research on detection or diagnosis of exposure}

\section{Self-Presenters}

First receivers willingness to respond to $\mathrm{CBRNe}$ contaminated casualties decreases when the substance is unknown ${ }^{34,35}$ 


\section{References}

1. Chilcott R, Wyke S. CBRN incidents. In: Sellwood C, Wapling, A (eds) Health Emergency Preparedness and response. Oxfordshire: CABI; 2016: 166-180.

2. Cabinet Office. Civil Contingencies Act 2004: a short guide. 2004:2-12. Essex Website. https://www.essex.gov.uk/Your-Council/Local-GovernmentEssex/Documents/15mayshortguide.pdf. Accessed May 15, 2018.

3. Whetzel E, Walker-Cillo G, Chan GK, Trivett J. Emergency nurse perceptions of individual and facility emergency preparedness. J Emerg Nurs. 2013;39(1):46-52.

4. Leiba A, Halpern P, Priel IE, et al. A Terrorist Suicide Bombing at a Nightclub in Tel Aviv: Analyzing Response to a Nighttime, Weekend, Multi-Casualty Incident. $J$ Emerg Nurs. 2006;32(4):294-298.

5. Mitchell CJ, Kernohan WG, Higginson R. Are emergency care nurses prepared for chemical, biological, radiological, nuclear or explosive incidents? Int Emerg Nurs. 2012;20(3):151-161.

6. Koenig KL. Strip and Shower : The Duck and Cover for the 21st Century. Ann Emerg Med. 2003;42(3):391-394.

7. Bland D. Training HazMat Training For Emergency Departments. In: Chemical Hazards and Poisons Report Incident Reponse: Industrial Fires. Health Protection Agency; 2006:45-58.

8. Smith B, Bouchoucha S, Watt E. "Care in a chair" - The impact of an overcrowded Emergency Department on the time to treatment and length of stay of self-presenting patients with abdominal pain. Int Emerg Nurs. 2016;29:9-14. 
9. Levitin HW, Siegelson HJ, Dickinson S, et al. Decontamination of mass casualties-reevaluating existing dogma. Prehosp Disaster Med. 2003;18(3):200-207.

10. Mcfee R, Leiken J. Death by Polonium-210: lessons learned from the mruder of former soviet spy Alexander Litvinenko. Semin Diagn Pathol. 2009;18-23.

11. Kaji AH, Langford V, Lewis RJ. Assessing Hospital Disaster Preparedness: A Comparison of an On-Site Survey, Directly Observed Drill Performance, and Video Analysis of Teamwork. Ann Emerg Med. 2008;52(3):195-201.

12. O'Sullivan TL, Dow D, Turner MC, et al. Disaster and emergency management: Canadian nurses' perceptions of preparedness on hospital front lines. Prehosp Disaster Med. 2008;23(3):11-8.

13. Williams J, Walter D, Challen K. Preparedness of emergency departments in Northwest England for managing chemical incidents : a structured interview survey. BMC Emerg Med. 2007;7(20):1-5.

14. Anathallee M, Curphey A, Beeching N, Carley S, Crawford I, Mackway-Jones K. Emergency departments (EDs) in the United Kingdom (UK) are not prepared for emerging biological threats and bioterrorism. $J$ Infect. 2007;54(1):12-17.

15. Kollek D. Canadian emergency department preparedness for a nuclear, biological or chemical event. CJEM. 2003; 5 (1): 18-26.

16. Kotora JG. An assessment of Chemical, Biological, Radiologic, Nuclear, and Explosive preparedness among emergency department healthcare providers in an inner city emergency department. J Emerg Manag. 2015;13(5):431-436.

17. Pluye P, Gagnon MP, Griffiths F, Johnson-Lafleur J. A scoring system for appraising 
mixed methods research, and concomitantly appraising qualitative, quantitative and mixed methods primary studies in Mixed Studies Reviews. Int J Nurs Stud. 2009;46(4):529-546.

18. Niska RW, Burt CW. Bioterrorism and mass casualty preparedness in hospitals: United States, 2003. Adv Data. 2005;(364):1-14.

19. Timm N, Reeves S. A mass casualty incident involving children and chemical decontamination. Disaster Manag Response. 2007;5(2):49-55.

20. Masterson L, Steffen C, Brin M, Kordick MF, Christos S. Willingness to respond: of emergency department personnel and their predicted participation in mass casualty terrorist events. $J$ Emerg Med. 2009;36(1):43-49.

21. Jasper E, Miller, M, Sweeney, B, Berg, D, Feuer, E, \& Reganato D. Preparedness of hospitals to respond to a radiological terrorism event as assessed by a full-scale exercise. J Public Heal Manag Pract. 2005;11(6):11-16.

22. Wong K, Turner PS, Boppana A, et al. Preparation for the next major incident: are we ready? Emerg Med J. 2006;23:709-712.

23. Kollek D, Cwinn A. A hospital emergency readiness overview study. Prehosp Disaster Med. 2011;26(3):159-165.

24. Schultz CH, Koenig KL, Whiteside M, Murray R. Development of national standardized all-hazard disaster core competencies for acute care physicians, nurses, and EMS professionals. Ann Emerg Med. 2012;59(3):196-208.

25. Djalali A, Della Corte F, Segond F, et al. TIER competency-based training course for the first receivers of CBRN casualties. Eur J Emerg Med. 2016; 24 (5):371-376. 
26. Klima DA, Seiler SH, Peterson JB, et al. Full-scale regional exercises. J Trauma Acute Care Surg. 2012;73(3):592-598.

27. Reddy MC, Paul SA, Abraham J, McNeese M, DeFlitch C, Yen J. Challenges to effective crisis management: Using information and communication technologies to coordinate emergency medical services and emergency department teams. Int J Med Inform. 2009;78(4):259-269.

28. Zhu S, Abraham J, Paul SA, et al. R-CAST-MED: Applying intelligent agents to support emergency medical decision-making teams. Artif Intell Med Proc. 2007;4594:24-33.

29. Becker SM, Middleton SA. Improving hospital preparedness for radiological terrorism: perspectives from emergency department physicians and nurses. Disaster Med Public Heal Prep. 2008;2:174-184.

30. Considine J, Mitchell B. Chemical, biological and radiological incidents: Preparedness and perceptions of emergency nurses. Disasters. 2009;33(3):482-497.

31. Oh JJ, Yong R, Ponampalam R, Anantharman V, Lim SH. Mass casualty incident involving pepper spray exposure: Impact on the emergency department and management of casualties. Hong Kong J Emerg Med. 2010;17(4):352-359.

32. Treat KN, Williams JM, Furbee PM, Manley WG, Russell FK, Stamper CD. Hospital preparedness for weapons of mass destruction incidents: An initial assessment. Ann Emerg Med. 2001;38(5):562-565.

33. Kollek D. Canadian emergency department preparedness for a nuclear, biological or chemical event. CJEM. 2003;5(1):18-26. 
34. Masterson \& Kordick SC. Willingness to respond: a survey of emergency department personnel and their predicted participation in mass casualty terrorist events. Res forum Abstr. 2004;363(1869):1870.

35. Cone DC, Cummings BA. Hospital disaster staffing: if you call, will they come? Am J Disaster Med. 2006;1(1):28-36.

36. Waage S, Poole JC, Thorgersen EB. Rural hospital mass casualty response to a terrorist shooting spree. Br J Surg. 2013;100(9):1198-1204. doi:10.1002/bjs.9203

37. Durukan P, Ozdemir C, Coskun R, et al. Experiences with endosulfan mass poisoning in rural areas. Eur J Emerg Med. 2009;16(1):53-56.

38. Raiter Y, Farfel A, Lehavi O, et al. Mass casualty incident management, triage, injury distribution of casualties and rate of arrival of casualties at the hospitals: lessons from a suicide bomber attack in downtown Tel Aviv. Emerg Med J. 2008;25(4):225-229.

39. Satterthwaite PS, Atkinson CJ. Using "reverse triage" to create hospital surge capacity: Royal Darwin Hospital's response to the Ashmore Reef disaster. Emerg Med J. 2012;29:160-162.

40. Shah AA, Rehman A, Sayyed RH, et al. Impact of a predefined hospital mass casualty response plan in a limited resource setting with no pre-hospital care system. Injury. 2015;46(1):156-161.

41. Castle N. Care after chemical, biological, radiation or nuclear events: Emerg Nurse. $2010 ; 18(7), 26-26$.

42. Cohen DC, Sevdalis N, Patel V, Taylor D, Batrick N, Darzi AW. Major incident preparation for acute hospitals: Current state-of-the-art, training needs analysis, and the 
role of novel virtual worlds simulation technologies. J Emerg Med. 2012;43(6):10291037.

43. Brinker A, Gray SA, Schumacher J. Influence of air-purifying respirators on the simulated first response emergency treatment of CBRN victims. Resuscitation. $2007 ; 74(2): 310-316$

44. Schumacher J, Bond AR, Woodham V, Buckingham A, Garnham F, Brinker A. Survey of UK Health Care First Responders' Knowledge of Personal Protective Equipment Requirements. Prehosp Disaster Med. 2015;30(3):254-258.

45. George G, Ramsay K, Rochester M, et al. Facilities for chemical decontamination in accident and emergency departments in the United Kingdom. Emerg Med J. 2002;19(5):453-457.

46. Wetter DC, Daniell WE, Treser CD. Hospital preparedness for victims of chemical or biological terrorism. Am J Public Health. 2001;91(5):710-716.

47. Castle N, Bowen J, Spencer N. Does wearing CBRN-PPE adversely affect the ability for clinicians to accurately, safely, and speedily draw up drugs? Clin Toxicol (Phila). 2010;48(6):522-527.

48. Flaishon R, Sotman A, Ben-Abraham R, Rudick V, Varssano D, Weinbroum A a. Antichemical protective gear prolongs time to successful airway management: a randomized, crossover study in humans. Anesthesiology. 2004;100(2):260-266.

49. Castle N, Owen R, Hann M, Clark S, Reeves D, Gurney I. Impact of chemical, biological, radiation, and nuclear personal protective equipment on the performance of low- and high-dexterity airway and vascular access skills. Resuscitation. 2009;80(11):1290-1295. 
50. Whetzel E, Walker-Cillo G, Chan GK, Trivett J. Emergency nurse perceptions of individual and facility emergency preparedness. J Emerg Nurs. 2013;39(1):46-52.

51. Labrague LJ, Hammad K, Gloe DS, et al. Disaster preparedness among nurses: A systematic review of literature. Int Nurs Rev. 2017:1-13.

52. Wilson JR. Fundamentals of systems ergonomics. Work. 2012;41(SUPPL.1):38613868.

53. Barnett DJ, Thompson CB, Errett NA, et al. Determinants of emergency response willingness in the local public health workforce by jurisdictional and scenario patterns: A cross-sectional survey. BMC Public Health. 2012;12(1):164.

54. Maxwell C. Hospital organizational response to the nuclear accident at Three Mile Island: implications for future-oriented disaster planning. Am J Public Health. $1982 ; 72(3): 275-279$.

55. Ochi S, Tsubokura M, Kato S, et al. Hospital staff shortage after the 2011 triple disaster in Fukushima, Japan-an earthquake, tsunamis, and nuclear power plant accident: A case of the Soso district. PLoS One. 2016;11(10):1-12.

56. Ashkenazi I, Kessel B, Khashan T, et al. Precision of in-hospital triage in masscasualty incidents after terror attacks. Prehosp Disaster Med. 2006;21(1):20-23.

57. Malik ZU, Hanif MS, Tariq M, et al. Mass casualty management after a suicidal terrorist attack on a religious procession in Quetta Pakistan. J Coll Physicians Surg Pakistan. 2006;16(4):253-256.

58. Schumacher J, Arlidge J, Garnham F, Ahmad I. A randomised crossover simulation study comparing the impact of chemical, biological, radiological or nuclear substance 
personal protection equipment on the performance of advanced life support interventions. Anaesthesia. 2017;72(5):592-597.

59. Health Protection Agency: CBRN Incidents : Clinical Management \& Health Protection. Gov UK website. https://www.gov.uk/ (https://www.gov.uk/government/uploads/system/uploads/attachment_data/file/340709 /Chemical_biological_radiological_and_nuclear_incidents_management.pdf.) Accessed May 16, 2018.

60. NHS England Emergency Preparedness, Resilience and Response (EPRR): Planning for the management of self-presenting patients in healthcare settings. NHS England Website. https://www.england.nhs.uk/ourwork/eprr/ (http://webarchive.nationalarchives.gov.uk/20161104231146/https://www.england.nhs. uk/wp-content/uploads/2015/04/eprr-chemical-incidents.pdf.) Accessed 17 May, 2018

61. Core Standards for Emergency Preparedness, Resilience and Response (EPRR). NHS England Web site. https://www.england.nhs.uk (https://www.england.nhs.uk/wpcontent/uploads/2015/06/nhse-core-standards-150506.pdf.) . Accessed May 17, 2018.

62. Home Office. Initial Operational Response To a CBRN Incident. 2015; http://www.jesip.org.uk/uploads/media/pdf/CBRN JOPs/IOR_Guidance_V2_July_2015.pdf. Publsihed 2015. Accessed May 17, 2018

63. National Ambulance Resillience Unit. Initial Operational Response for the wider NHS. NARU website https://naru.org.uk/videos/ior-nhs/. Accessed May 16, 2018.

64. Morelli I, Sabbadini MG, Bortolin M. Orthopedic injuries and their treatment in children during earthquakes: A systematic review. Prehosp Disaster Med. 2015;30(5):478-485. 
65. Lee ACK, Booth A, Challen K, Gardois P, Goodacre S. Disaster management in lowand middle-income countries: scoping review of the evidence base. Emerg Medcine J. 2014;31(1):78-83.

66. Challen K, Lee AC, Booth A, Gardois P, Woods HB, Goodacre SW. Where is the evidence for emergency planning: a scoping review. BMC Public Health. $2012 ; 12(1): 542$. 
1. (hospital OR emergency department OR ED OR accident and emergency dep* OR A\&E OR self present OR self presen* OR walking wounded OR p3) AND (CBRN"OR CBRNE OR mass casualty inciden*" OR mass casualty event OR mass casua*) AND (detection OR decontamination UR diagnosis UR equipment UR technologies) NUI (teaching UR training OR education)

2. ("hospital" OR "emergency department" OR "self presen*") AND ("CBRN" OR "CBRNE" OR "unass casual") AND ("detectivu" OR "decuntaminativu" OR "diagnusis") AND("equipment" OR "technologies") NOT ("training" OR “teaching" OR "education")

3. ("hospital" OR "emergency department" OR "ED" OR "accident and emergency dep*" OR " $A \& E$ ") OR ("self present" OR "self presen*" OR "walking wounded" OR "p3" OR "patient*") AND ("cbrn" OR "cbrne" OR "mass casualty inciden*" OR "mass casualty event" OR "mass casua*”) AND ("detection" OR "decontamination" OR "diagnosis" AND "equipment" OR “technologies" OR" tech*”) AND NOT (“teaching”)

\section{Example of search strings}

$254 \times 190 \mathrm{~mm}(300 \times 300$ DPI) 


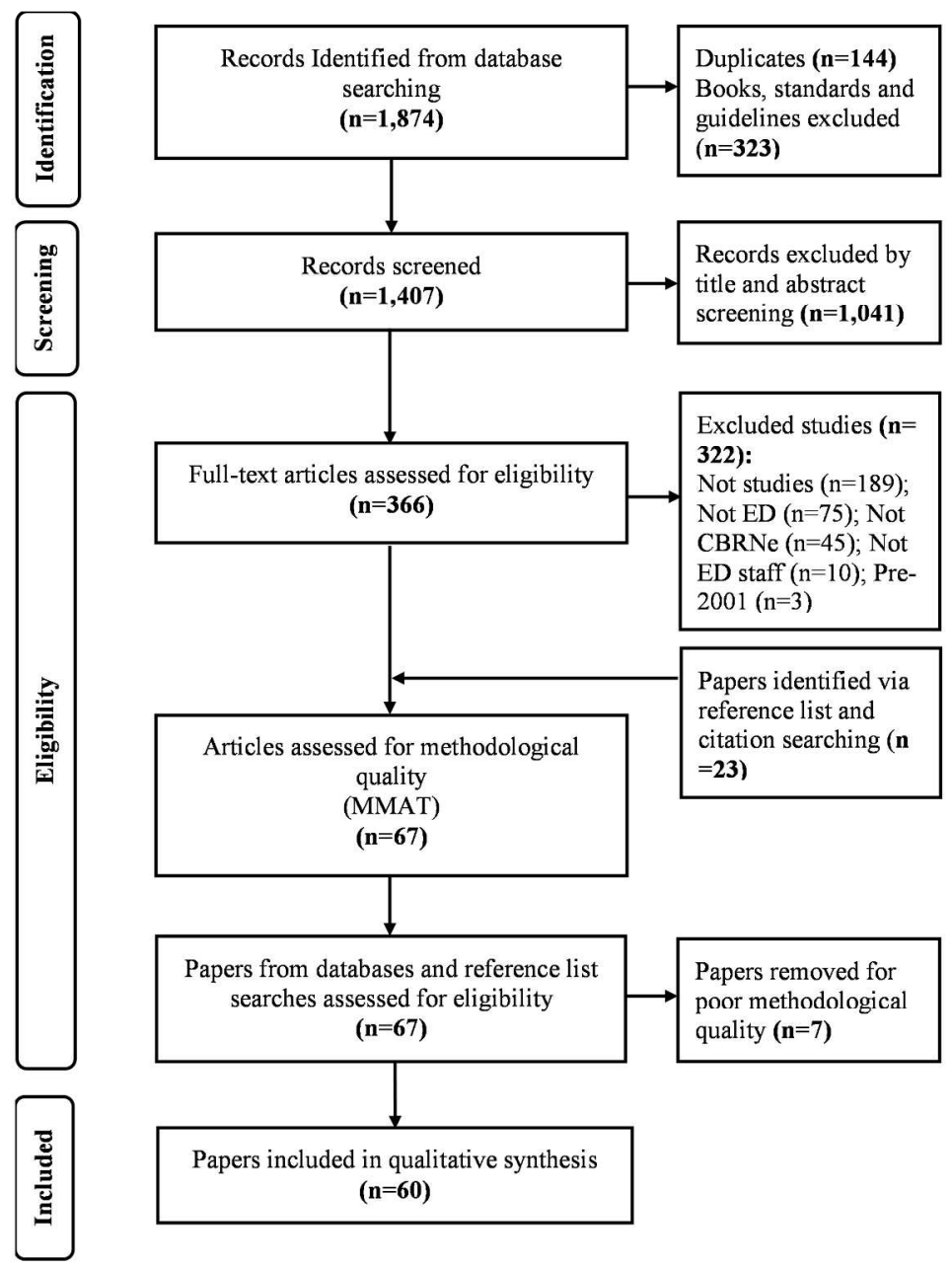

PRISMA flow diagram of studies included in the systematic review $190 \times 254 \mathrm{~mm}(300 \times 300 \mathrm{DPI})$ 


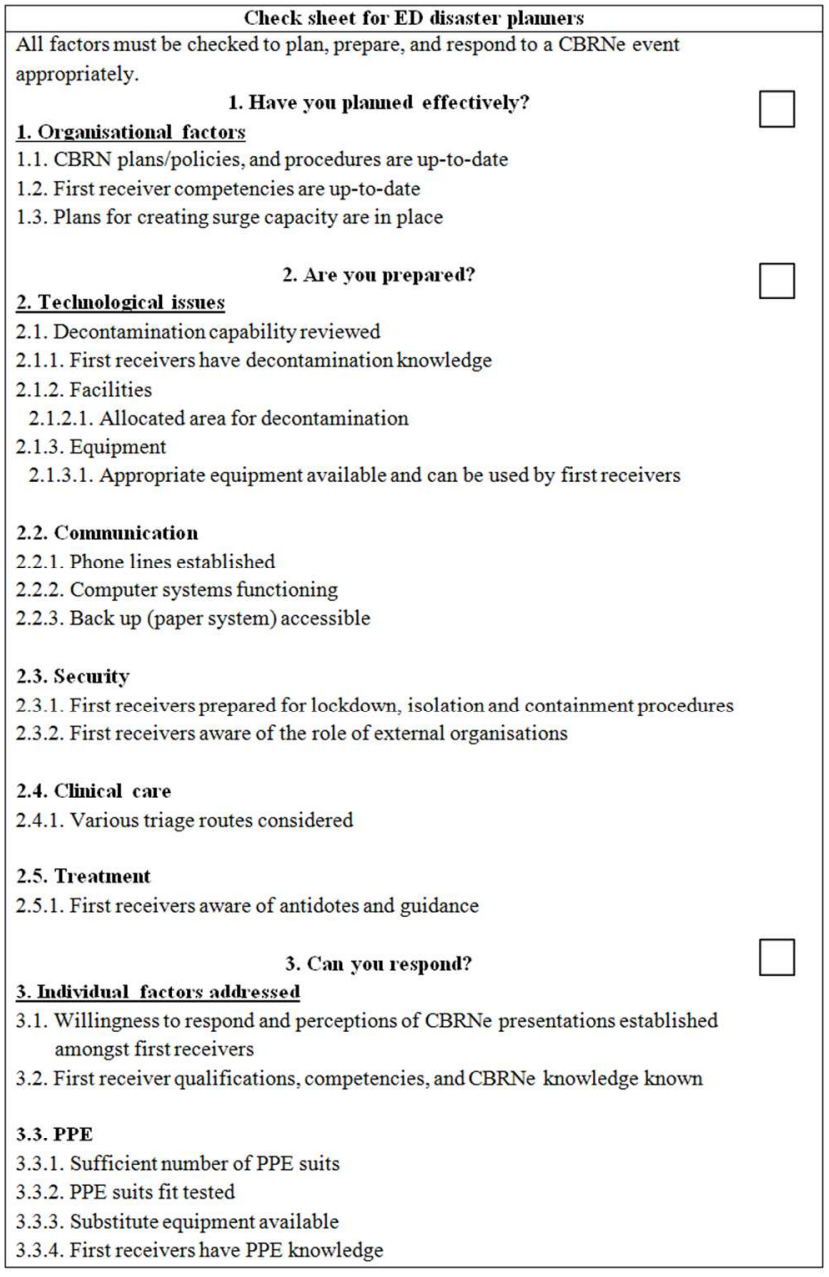

Checksheet for ED disaster planners based on the findings of the systematic review $190 \times 254 \mathrm{~mm}(300 \times 300 \mathrm{DPI})$ 